\title{
Observation of two distinct cold, dense ion populations at geosynchronous orbit: local time asymmetry, solar wind dependence and origin
}

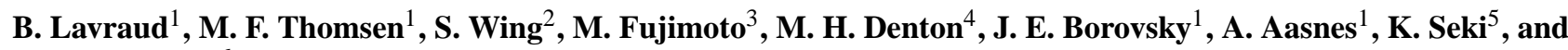 \\ J. M. Weygand ${ }^{6}$ \\ ${ }^{1}$ Space Science and Applications, Los Alamos National Laboratory, Los Alamos, New Mexico, USA \\ ${ }^{2}$ The Johns Hopkins University, Applied Physics Laboratory, Laurel, Maryland, USA \\ ${ }^{3}$ Tokyo Institute of Technology, Meguro, Tokyo, Japan \\ ${ }^{4}$ Department of Communications Systems, Lancaster University, Lancaster, UK \\ ${ }^{5}$ Solar-Terrestrial Environment Laboratory, University of Nagoya, Aichi, Japan \\ ${ }^{6}$ Institute of Geophysics and Planetary Physics, UC Los Angeles, California, USA
}

Received: 20 July 2006 - Revised: 2 November 2006 - Accepted: 8 November 2006 - Published: 21 December 2006

\begin{abstract}
We report on the observation of two distinct cold $\left(T_{i}<5 \mathrm{keV}\right)$, dense $\left(N_{i}>2 \mathrm{~cm}^{-3}\right)$ ion populations at geosynchronous orbit. A statistical study was performed on measurements from the geosynchronous Los Alamos plasma instruments, for the period 1990-2004, and complemented by corresponding large-scale plasma sheet data obtained by mapping DMSP observations in the tail. The first population, which has previously been reported in several studies, is observed in the midnight region of geosynchronous orbit. The second population, which has drawn less attention, is detected on the dawn side of geosynchronous orbit. No such cold, dense population is observed on the dusk side of geosynchronous orbit on a frequent basis. The temporal evolution of various plasma parameters as a function of local time shows that the two populations appear at geosynchronous orbit as distinct populations, since the appearance of a midnight population is not usually associated with that of a dawn population, and vice versa. The midnight ion population is typically observed after the IMF has been northward for some time and is convected inward toward geosynchronous orbit after an observed mild southward turning of the average IMF. It is interpreted that the source of the midnight population is the cold, dense plasma sheet (CDPS). The dawn-side cold and dense ion population is associated with previously strong southward IMF and consequently occurs during substantial geomagnetic activity. These events are typically observed around the end of the main phase of the corresponding Dst decrease, down to $-50 \mathrm{nT}$ on average. It is unlikely that this dawn population is simply the low-latitude boundary layer (LLBL) moving closer to Earth

Correspondence to: B. Lavraud

(lavraud@lanl.gov)
\end{abstract}

because (1) no symmetric dusk population is observed and (2) on average a small sunward flow $(\sim 15 \mathrm{~km} / \mathrm{s})$ is observed for those events. The cold, dense population at dawn is thus observed during active times (based on $D_{s t}, K_{p}$ and $A_{E}$ indices) in comparison with the midnight case. However, since the dawn population is observed only around the end of the main $D_{s t}$ decrease, it is concluded that this population does not typically contribute to the $D_{s t}$ decrease during the main phase. This population may rather be transported to geosynchronous orbit by means of a compression and convection enhancement in the magnetosphere, with a preferential access from the dawn flank with no apparent counterpart at dusk. DMSP data suggest that a cold and dense plasma source is mainly present at dawn.

Keywords. Magnetospheric physics (Magnetospheric configuration and dynamics; Plasma sheet) - Space plasma physics (Transport processes)

\section{Introduction}

Previous studies have shown that plasma sheet access to geosynchronous orbit is correlated with the $K_{p}$ and $D_{s t}$ magnetospheric activity indices (Korth et al., 1999; Denton et al., 2005). The former index is a proxy for the convection electric field strength (e.g., Thomsen, 2005) while the latter gives an estimate of the ring current strength (Dessler and Parker, 1959; Vasyliunas, 2006). The $D_{s t}$ and $K_{p}$ indices are further linked to conditions upstream in the solar wind, as a result of the large-scale coupling between Earth's magnetosphere and the solar wind (e.g., Burton et al., 1975).

Published by Copernicus GmbH on behalf of the European Geosciences Union. 
The occasional observation of cold and dense plasma sheet at geosynchronous orbit has been noted in several studies (e.g., Thomsen et al., 2003; Lavraud et al., 2005). It has been suggested in particular that the density of the plasma sheet having access to the inner magnetosphere through geosynchronous orbit may have an impact on the ensuing magnetospheric activity (e.g., Borovsky et al., 1998; Jordanova et al., 1998; Kozyra et al., 1998; Thomsen et al., 1998). The studies by Thomsen et al. (2003) and Lavraud et al. (2005) showed that the observation of cold and dense plasma at geosynchronous orbit is likely due to the inward transport of the cold, dense plasma sheet (CDPS) that is occasionally observed in the tail of the magnetosphere (c.f. Lennartsson and Shelley, 1986; Zwolakowska et al., 1992; Terasawa et al., 1997; Fujimoto et al., 1998; Phan et al., 2000). Because of its composition, the CDPS has been attributed a solar wind origin (Lennartsson, 1992). Its formation strongly depends on the interplanetary magnetic field (IMF) direction, being typically observed after long periods of northward IMF (Terasawa et al., 1997; Fujimoto et al., 2002). Two main mechanisms have been proposed to account for its formation: (1) solar wind plasma penetration via Kelvin-Helmholtz instability at the flank magnetopause (Fujimoto et al., 1998; Hasegawa et al., 2004) and (2) solar wind "direct" capture on newly closed field lines at the dayside magnetopause, by double high-latitude reconnection of magnetosheath field lines (Song and Russell, 1992; Raeder et al., 1997; Øieroset et al., 2005; Lavraud et al., 2006a). Also, it is noted that events of "super-dense" plasma sheet at geosynchronous orbit are not always unusually cold (Borovsky et al., 1997; Thomsen et al., 2003; Lavraud et al., 2005). These have been interpreted as the result of different solar wind conditions, e.g., non-northward IMF but dense solar wind, possibly associated with different plasma sheet formation mechanisms and processing (transport and acceleration) in the magnetotail.

Geosynchronous spacecraft are located at the inner edge of the plasma sheet and therefore constitute ideal tools for exploring the transport of plasma populations to the inner magnetosphere. From geosynchronous observations, Borovsky et al. (1997) showed that the plasma sheet typically has densities in the range $0.4-2 \mathrm{~cm}^{-3}$, with an average density of $0.7 \mathrm{~cm}^{-3}$ in the midnight region. They also put forth the appearance of a distinct higher density distribution above $2 \mathrm{~cm}^{-3}$, which they referred to as "super-dense" plasma sheet events. Lavraud et al. (2005) focused on the access of such dense plasma populations to geosynchronous orbit. They showed that dense plasma observations primarily occur in the midnight region of geosynchronous orbit, presumably as a result of modestly enhanced convection leading to plasma sheet inward transport. They only focused on the occurrence of high density plasma and noted the frequent appearance of a dense plasma population at dawn of geosynchronous orbit as well, which appeared to have generally low temperatures. A similar population appeared in earlier analyses (e.g., Korth et al., 1999; Denton et al., 2005) but received no particular attention then.

Fujimoto et al. $(2002,2005)$ noted that the cold, dense plasma sheet (with densities above $1 \mathrm{~cm}^{-3}$ and temperatures below $2 \mathrm{keV}$ ) in the mid-tail regions may be observed equally at dawn and dusk. By contrast, a hotter $(>2 \mathrm{keV})$ and dense population (hot, dense ions; HDI) is often detected at the inner edge of the CDPS on the dawn side, but not on the dusk side. In the present follow up of the study by Lavraud et al. (2005), we investigate the occurrence of both dense and cold ion populations at geosynchronous orbit. We particularly focus on the appearance of distinct populations at midnight and dawn. We analyze geosynchronous, solar wind, geomagnetic activity, and DMSP data to obtain clues on (1) the local time distribution of the access of these plasma populations, (2) their respective origin and transport path, and (3) their potential impact on magnetospheric dynamics.

In the next section, we present the data used in this study and the processing methods. In Sect. 3, we present the results of the analysis, which we discuss in Sect. 4. Section 5 draws the conclusions.

\section{Instrumentation and data processing}

\subsection{Los Alamos geosynchronous data}

We use ion and electron measurements from the Los Alamos MPA (Magnetospheric Plasma Analyzer) instruments onboard geosynchronous satellites. The MPA instruments are electrostatic analyzers. They measure the three-dimensional energy-per-charge distributions of ions and electrons between $\sim 1 \mathrm{eV} / \mathrm{q}$ and $\sim 45 \mathrm{keV} / \mathrm{q}$. Here we use ion density and temperature measurements which are available every $86 \mathrm{sec}-$ onds (Thomsen et al., 1999) and are calculated for the energy range $100-45000 \mathrm{eV}$. The reader is referred to Bame et al. (1993) and McComas et al. (1993) for detailed description of the MPA instruments.

For the current study, data are taken from seven different satellites in geosynchronous orbit covering the period between 1990 and 2004. Section 3.1 first deals with a largescale analysis of the whole data set, which is performed to obtain statistics of plasma events characterized by various densities and temperatures. These allow us to study the local time dependence and occurrence statistics as a function of the selected density and temperature criteria. The "zero epochs" used for the superposed epoch analyses performed in the following sections come from a list of 644 initial events which are found to be unusually dense $\left(>2 \mathrm{~cm}^{-3}\right)$ and cold $(T<5 \mathrm{keV})$ simultaneously. The zero epochs are defined as the time at which one of the operating spacecraft, during one given day and with a minimum delay of $12 \mathrm{~h}$ between two consecutive events (the same event would be counted multiple times otherwise), measures such cold, dense plasma for the first time (with at least two such measurements contiguous to avoid spurious data points). Events from all local 
times are analyzed first in Fig. 1, after which we only focus on the two separate populations observed at midnight and dawn. For all measurements used in the study, most magnetosheath and "flowing" low-latitude boundary layer (LLBL) encounters were removed by only accepting data points with proton density lower than $10 \mathrm{~cm}^{-3}$ and proton bulk speed lower than $100 \mathrm{~km} / \mathrm{s}$. Owing to spacecraft charging effects, we have also excluded data points recorded when the charging exceeds $70 \mathrm{keV}$, so that it may not affect ion spectra in the energy range for moments computation $(100-45000 \mathrm{eV})$.

\subsection{Solar wind and geomagnetic activity data}

Solar wind data and geomagnetic indices used in this study come from the OMNI2 data set (King and Papitashvili, 2005) and have $1 \mathrm{~h}$ resolution (the $K_{p}$ index is $3 \mathrm{~h}$ resolution). Although this resolution is coarser than the resolution used in the superposed epoch plots of Fig. 3, we used OMNI2 data interpolated at $10 \mathrm{~min}$ resolution in these plots in order to be comparable to the other superposed epoch plots in this study. The global trends, which are of interest here and which typically last for several hours, are therefore presumably meaningful. The coordinate system used is GSM.

\subsection{DMSP low-altitude data and mapping technique}

We also use data obtained from the SSJ4 instruments on board DMSP satellites. DMSP are Sun-synchronous satellites in nearly circular polar orbit at an altitude of roughly $835 \mathrm{~km}$ and a period of approximately $101 \mathrm{~min}$. The SSJ4 instruments are curved plate electrostatic analyzers which measure ions and electrons from $32 \mathrm{eV}$ to $30 \mathrm{keV}$ (Hardy et al., 1984). Complete electron and ion energy spectra are obtained every second. The satellites are three-axis stabilized and the detector apertures always point toward local zenith. This means that the observed fluxes are largely within the atmospheric loss cone. There were generally several satellites in operation during any given event of this study. This allows an optimal spatial coverage as each satellite covers different local times.

It is known that ions ( $6 \mathrm{keV}$ and above) observed in the topside ionosphere are isotropic above a certain latitude (e.g., Bernstein et al., 1974). In situ magnetotail observations, tailward of $\sim 8-10 R_{E}$, have also indicated that the plasma sheet is nearly isotropic, irrespective of activity levels (e.g., Kistler et al., 1992; Huang and Frank, 1994). Consequently, density, temperature, and pressure are approximately conserved along the magnetic field. The ions maintain their isotropy by pitch angle scattering in the tail current sheet (Lyons and Speiser, 1982). Closer to Earth (typically earthward of $\sim 8-10 R_{E}$ ), field lines become more dipolar and pitch angle scattering ceases. As a result, the mapping technique does not work in this region. Newell et al. (1998) have developed an algorithm to identify the equatorward isotropy boundary in the ionosphere (b2i) (equivalently the earthward boundary of the plasma sheet). Sergeev et al. (1993) showed that the ion isotropy boundary (i.e., b2i) highly correlates with the tail inclination angle measured in the same local time sector by GOES (correlation coefficient $=0.9$ ). Therefore b2i can be used to modify and improve ionosphere-magnetosphere T89 magnetic field model (Tsyganenko, 1989) tail mapping (Sergeev et al., 1993) and has been adapted into the method used here. More complete method descriptions may be found in Wing and Newell (1998) and Newell and Wing (2000).

Electron acceleration events are excluded from the data set because they distort the plasma sheet ion spectra, resulting in distributions that do not represent those in the plasma sheet. Each ion spectrum is fitted to distribution functions (one-component Maxwellian, two-component Maxwellian, and Kappa) and the best fit is selected. The moments obtained from those fits thus take into account ions from outside the detectors' energy range. Therefore, the densities obtained, in particular, can be larger than those calculated using straight integration of the distribution functions. But as will be apparent, the relative behaviors of the ion density and temperature constitute the most relevant observation in the context of the present study.

Using this method and DMSP data, we have constructed plots of the two-dimensional equatorial plasma sheet density and temperature for three different time intervals. Those intervals are $[-6,0],[0,4]$ and $[+4,+10]$ in epoch time, based on the zero epochs of observation of a cold and dense plasma sheet at geosynchronous orbit, as defined previously in Sect. 2.1. The data gathered in Figs. 6, 7 and 8 thus come from the same events as for geosynchronous observations, with several spacecraft typically operative during each event in both dataset, thus allowing for direct comparisons.

\section{Results}

\subsection{Local time distribution of plasma sheet access as a function of density and temperature}

Figure 1a shows the local time distribution ( $1 \mathrm{~h}$ bins) of the 644 cold $(T<5 \mathrm{keV})$ and dense $\left(N>2 \mathrm{~cm}^{-3}\right)$ plasma events observed from the survey of data from all satellites during the period 1990-2004 (cf. Sect. 2.1), and which are used as zero epoch times in the next sections. This distribution shows a tendency for cold, dense plasma events to occur close to midnight, but a comparable peak is observed around dawn. The occurrence then fades away each side of those peaks and towards the dayside. The distinct midnight and dawn events used later in Sect. 3.2 are shown between the blue and red vertical dashed lines, i.e., respectively between 21:00-03:00 and 03:00-09:00 LT.

To assess whether this feature is only specific of the populations meeting these particular criteria, we performed additional surveys of the dataset by varying the density and temperature thresholds. As noted in the introduction, the 

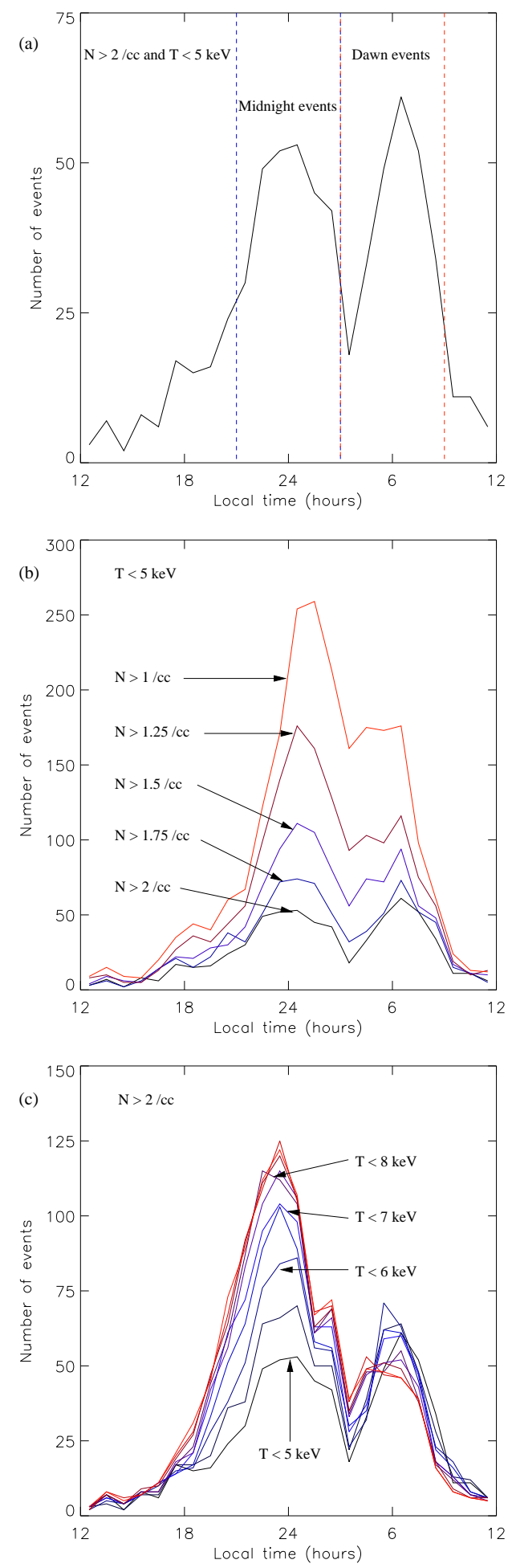

Fig. 1. Local time distributions of the occurrence of cold, and/or dense plasma events at geosynchronous orbit for (a) $N>2 \mathrm{~cm}^{-3}$ and $T<5 \mathrm{keV}$, (b) $T<5 \mathrm{keV}$ for five values of the density in the range $1-2 \mathrm{~cm}^{-3}$, and (c) $N>2 \mathrm{~cm}^{-3}$ for ten values of the temperature in the range $5000-9500 \mathrm{keV}$. See text for further details. plasma sheet at geosynchronous orbit has typically densities in the range $0.4-2 \mathrm{~cm}^{-3}$, with an average of $0.7 \mathrm{~cm}^{-3}$ in the midnight region (Borovsky et al., 1997).

Figure $1 \mathrm{~b}$ shows the local time distribution of events with temperatures lower than $5 \mathrm{keV}$ for five different density thresholds ranging from 1 to $2 \mathrm{~cm}^{-3}$ (by steps of $0.25 \mathrm{~cm}^{-3}$ ). This figure shows that less dense (e.g., red curve $N>1 \mathrm{~cm}^{-3}$ ) but cold events are recorded with a larger occurrence mostly around midnight. Although one can distinct two populations in this curve, a clear separation between midnight and dawn populations only becomes fully evident for dense plasmas above $1.5 \mathrm{~cm}^{-3}$, with the appearance of a large dip in occurrence between the two local time regions.

Similarly, Fig. 1c shows the local time distribution of events with densities above $2 \mathrm{~cm}^{-3}$ for ten different temperature thresholds ranging from 5 to $9.5 \mathrm{keV}$ (by steps of $500 \mathrm{eV}$, curves colors respectively go in the order black-blue-red). From these curves it appears that dense plasma events appear as increasingly distinct populations at midnight and dawn for progressively lower temperatures. A striking feature in Fig. 1c is the increase in the total number of events at dawn as the temperature threshold is decreased. This feature is due to the fact that a small fraction of the dense and relatively hot populations from midnight (these events are numerous; i.e., the red curve around the midnight region in Fig. 1c) are recorded during events when a colder and dense population is observed at dawn as well. We discuss this in Sect. 4.

From this analysis, we may so far conclude that the first appearance of cold, dense plasma occurs distinctly at both midnight and dawn with comparable occurrence. That the local time distribution shows two peaks at midnight and dawn, with a clear dip in between, shows that those are generally distinct populations. We will now focus on the properties of those events meeting the initial criteria $\left(N>2 \mathrm{~cm}^{-3}\right.$ and $T<5 \mathrm{keV}$ ) since those correspond to the original cold, dense ion populations of interest (cf. introduction). To understand the large-scale behavior and origin of plasmas at geosynchronous orbit during the two types of event (midnight and dawn), in the remainder of this paper we separately analyze solar wind data (and in the next sections Los Alamos MPA and DMSP data) for two subsets of the 644 initial cold $(T<5 \mathrm{keV})$, dense $\left(N>2 \mathrm{~cm}^{-3}\right)$ plasma events. The first set corresponds to "midnight" events observed first in the range (21:00-03:00 LT, with a total of 271 events. The second set corresponds to "dawn" events observed first in the range 03:00-09:00 LT, and totals 247 events (cf. Fig. 1a).

To quantify the likelihood of observation of such cold, dense plasma events at geosynchronous orbit, we kept track of the total number of measurements that have been analyzed in the midnight and dawn regions, respectively (as defined above). These correspond to a total of 2730 and 3054 days of satellite data, respectively for midnight and dawn. The likelihood of observation of a cold, dense event is thus respectively of $\sim 10 \%$ and $8 \%$. It must be remembered that our 
analysis does not specify any duration for the events, which will be addressed in future studies.

\subsection{Superposed epoch analysis of solar wind and geomag-} netic parameters

All data used in the superposed epoch plots of Fig. 2 come from the OMNI2 dataset (see Sect. 2.2). From top to bottom, the panels show (a) the solar wind (SW) dynamic pressure (Pram), (b) the SW density, (c) the SW speed, (d) the IMF absolute clock angle $\left(|C A|=\left|\tan ^{-1}\left(B_{Y} / B_{Z}\right)\right|\right)$, (e) the IMF magnitude, (f) the IMF $B z$ component, (g) the $D_{s t}$ index, (h) the $A_{E}$ index, and (i) the $K_{p}$ index. We have used all available data to perform superposed epoch averages of those parameters. The results from the superposition of all 644 cold, dense events (regardless of local time) are represented by the black line. The results from the superposition of the separate sets of midnight and dawn events are respectively displayed as the blue and red lines. The available solar wind data are limited compared to the coverage of the Los Alamos spacecraft. We have estimated that $72 \%$ and $69 \%$ of the total number of events (644) have a coverage of at least $70 \%$ of the interval (from -6 to $+10 \mathrm{~h}$ in epoch time in Fig. 2) for the magnetic field (e.g., IMF clock angle) and plasma data (e.g., dynamic pressure), respectively. Owing to the large number of events, the following results may be viewed as meaningful. Also, the $A_{E}$ index from the OMNI dataset is only available up to 1995 , but the trend of this index will be shown to be consistent with other parameters and is therefore worth noticing. $D_{s t}$ and $K_{p}$ coverage is complete. Note that, owing to the large number of events, statistical errors are very small and thus not shown in Fig. 2. The average deviation of the mean (i.e., the average deviation from the mean divided by the square root of the number of measurements) is typically of the order of a few percent of the absolute value for all parameters at all epoch times (apart from the $D_{s t}$ for the midnight events that is close to zero at early epoch times).

From the superposed epoch results of Fig. 2 we can see that cold, dense plasma at midnight is generally observed for mild solar wind and geomagnetic conditions. By contrast, cold, dense plasma observations at dawn correspond to active times.

The events for which first detection of cold, dense plasma occurs at midnight have (compared to the dawn events) (1) a lower dynamic pressure mainly in the period -2 to $+2 \mathrm{~h}$ in epoch time (panel a), (2) similar density and slightly lower velocity (panels b and c), (3) a modestly lower IMF strength both prior to and after zero epoch, (4) an average clear northward-directed IMF (panels d and f) prior to zero epoch and (5) a mild southward turning of the IMF toward more horizontal direction around zero epoch. The main property of those midnight events thus appears to be that it follows a substantial period of northward IMF, together with a slight southward turning of the IMF towards an average horizontal direction around zero epoch. This fact suggests that

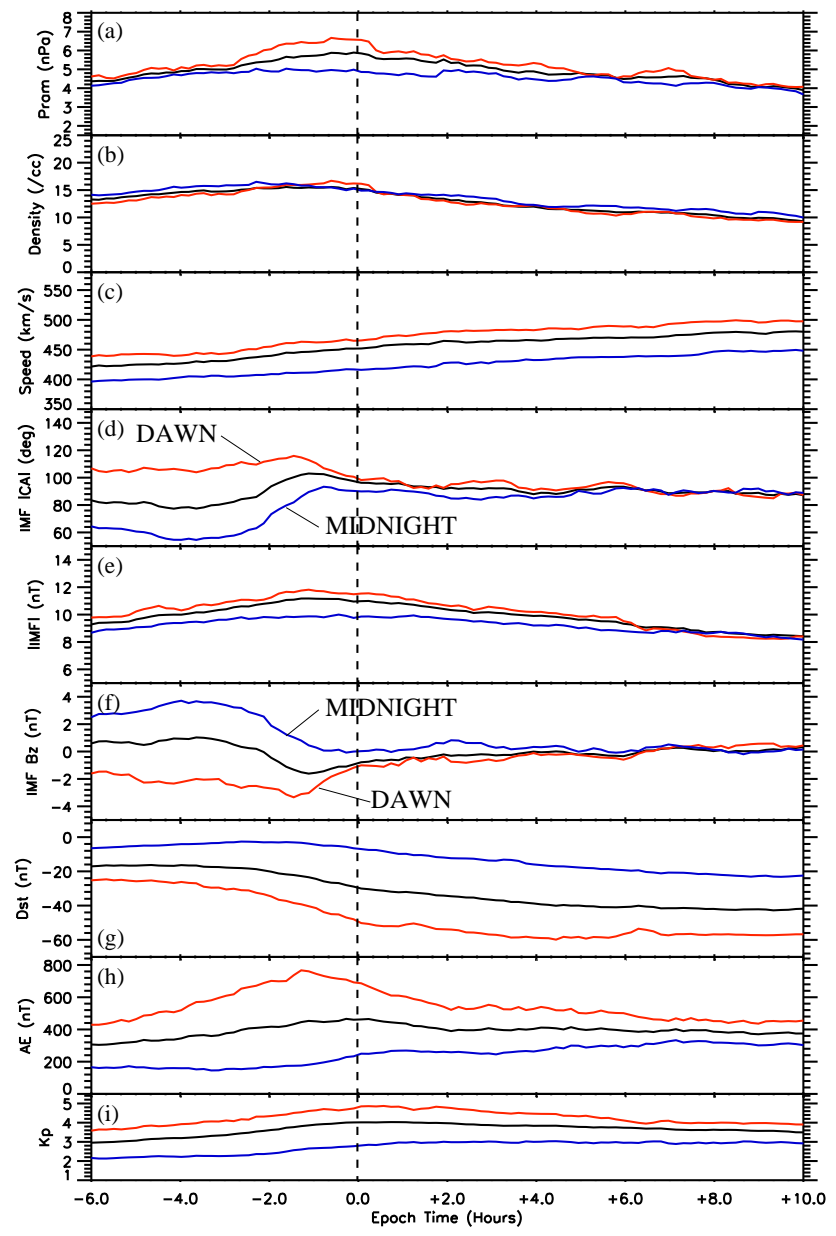

Fig. 2. Superposed epoch time series of solar wind and geomagnetic activity data for the two sets of events (from the OMNI2 dataset in GSM coordinates). The time series for the 271 (247) cold, dense plasma events occurring at midnight (dawn) is shown as the blue (red) line. The black line is that for all the events (644), from all local times. Owing to the large number of events, statistical errors are very small and therefore not shown. See text for further details.

cold, dense plasma is built in the tail plasma sheet during northward IMF, i.e., formation of a cold, dense plasma sheet (CDPS), and is later pushed inward through geosynchronous orbit by a modest southward turning of the IMF, presumably leading to a slight convection enhancement (Thomsen et al., 2003; Lavraud et al., 2005). The observation of a cold, dense ion population at midnight does not typically (i.e., on average) correspond to geomagnetic active times, as the $D_{s t}, K_{p}$ and $A_{E}$ indices only show relatively low levels.

By contrast, the observation of a cold and dense ion population at the dawn side of geosynchronous orbit does seem to be associated with substantial geomagnetic activity. The main features observed in the superposed epoch plot of Fig. 2 are an enhanced solar wind dynamic pressure before and around zero epoch and a substantial southward IMF prior to zero epoch. These solar wind conditions result in substantial 

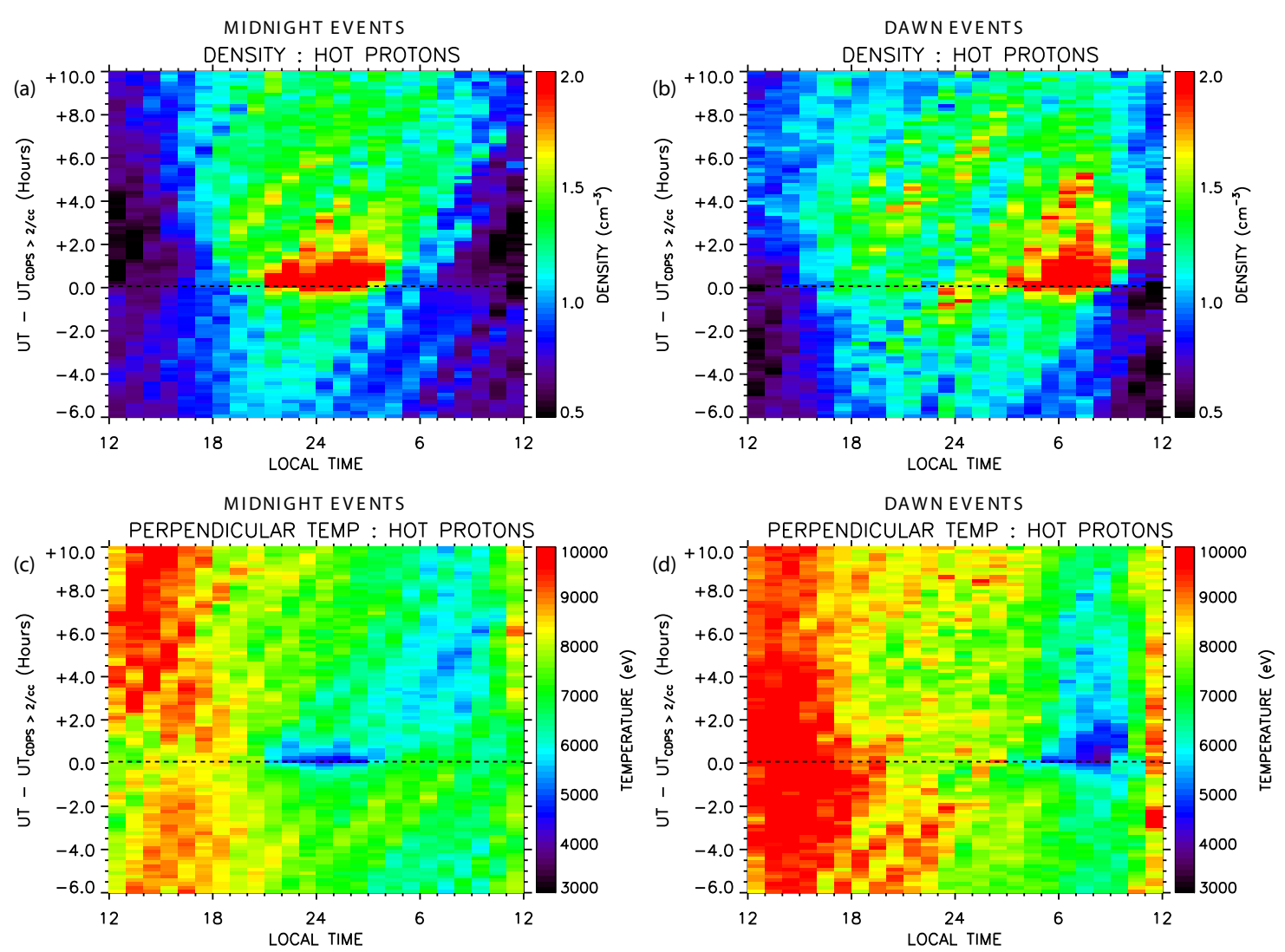

Fig. 3. Results of the superposed epoch analysis for various plasma parameters. For the plots in the left (right) column, the zero epoch times are those of the 271 (247) initial cold, dense plasma events from midnight (dawn). The measurements from all operating spacecraft are binned and averaged according to 24 local time bins (x-axis) and 96 ten-minute intervals in time. The total time interval ranges from $-6 \mathrm{~h}$ before to $+10 \mathrm{~h}$ after zero epoch (“0.0"). (a) and (b): superposed epoch plots of the ion density measurements. (c) and (d): superposed epoch plots of the perpendicular ion temperature. Respective color palettes are given on the right side of each plot. See text for further details.

geomagnetic activity with $D_{s t}$ decreasing as low as $-50 \mathrm{nT}$ on average. $K_{p}$ and $A_{E}$ indices also show significant increases in conjunction with the main phase of the $D_{s t}$ decrease. It is of particular interest to notice that (1) the appearance of this cold, dense population at dawn is actually observed after the main phase (i.e., at the end of the main average decrease in $D_{s t}$ ) and that (2) such preceeding conditions (i.e., the observed average southward IMF and the substantial dynamic pressure) also are conducive to magnetopause compression and erosion.

Finally, the superposed epoch results of the IMF $B_{y}$ component do not show any noticeable feature. The average values are close to zero for both kinds of events at all epoch times (not presented in Fig. 2). The frequent appearance of cold, dense plasma at dawn is thus likely unrelated to this component of the IMF.

\subsection{Superposed epoch analysis of plasma parameters for} the two distinct populations

In this section we investigate how frequently those two populations may appear during the same events. Figure 3 shows superposed epoch plots of ion density and temperature, with the $\mathrm{y}$-axis being the epoch time in hours and the $\mathrm{x}$-axis corresponding to the local time of observation. In these plots, all data from all operating spacecraft are used and binned into 96 ten-minute epoch time bins and 24 local time bins, and averages are made. The left- and right-hand side plots illustrate separately the midnight and dawn sets of events, respectively. Magnetosheath, LLBL and large spacecraft potential data points are removed throughout this study as explained in Sect. 2.1.

Figure $3 \mathrm{a}$ shows that very large densities are recorded near zero epoch around midnight. This is the result of our selection of only events for which enhanced densities were first seen in the midnight region between 21:00-03:00 LT. Low temperatures are observed at midnight around zero epoch (Fig. 3c) for the same reason. It is important to note that 

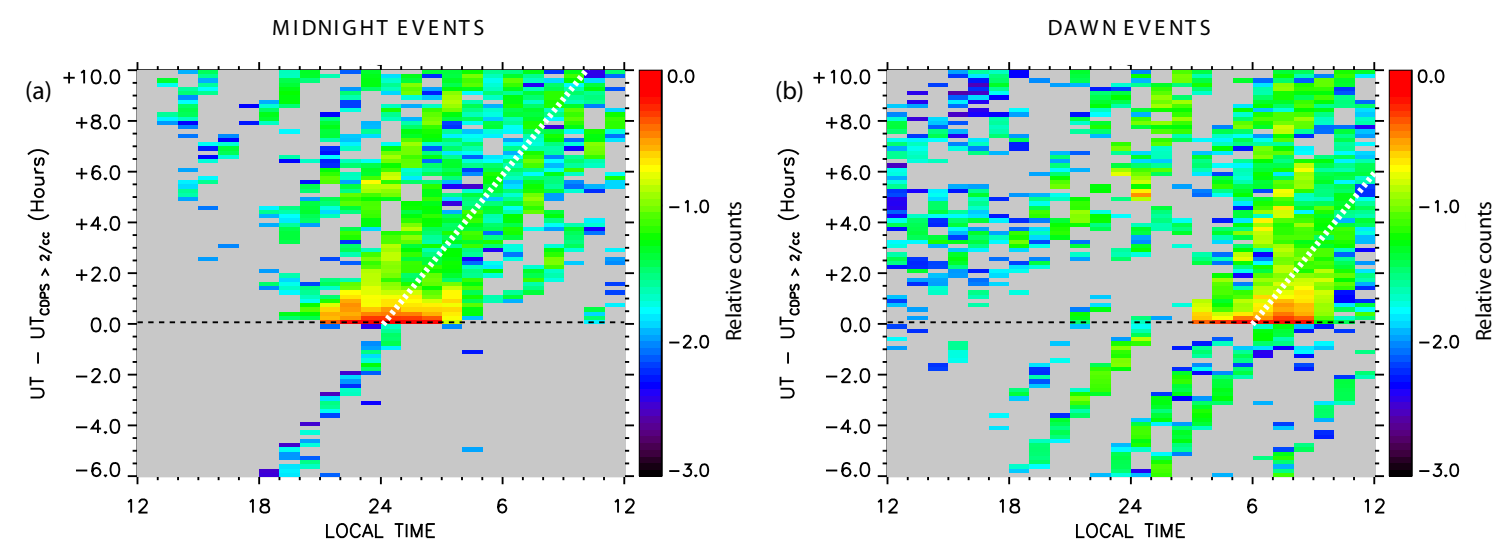

Fig. 4. Superposed epoch distributions of the relative number of measurements of cold $(<5 \mathrm{keV})$ and dense $\left(>2 \mathrm{~cm}^{-3}\right)$ ions for the midnight (a) and dawn (b) events. The number of cold, dense measurements, from all operating spacecraft, is binned according to 24 local time bins (x-axis) and 96 ten-minute intervals in time. This absolute number is then divided by the total number of measurements in each bin. Respective color palettes are given on the right side of each plot. Grey color means no count. See text for further details.

since those plots show averages of plasma parameters from all operating spacecraft, data at non-midnight local times near zero epoch come from the other operating spacecraft (up to seven).

Figure 3a shows a lack of dense plasma, on average, near dawn around zero epoch. This demonstrates that the observation of cold $(T<5 \mathrm{keV})$, dense $\left(N>2 \mathrm{~cm}^{-3}\right)$ plasma near midnight at geosynchronous orbit is not typically associated with cold, dense plasma observation at dawn at the same epoch time. Modestly dense plasma is observed at dawn later, after several hours in epoch time. This plasma is in addition relatively cold, thus suggesting the possibility that a portion of the cold, dense plasma populations at dawn occur during the midnight events but at later times (see Sects. 3.4 and 4). It should be remembered that ions at dawn are generally colder at all times owing to the continuous duskward magnetic drift of the highest energy ions (Maurice et al., 1998; Korth et al., 1999).

Figure $3 \mathrm{~b}$ shows the superposed epoch plot of the average density for the dawn cold and dense plasma events only. Large average densities are observed at dawn at zero epoch owing to the selection criteria. Correspondingly, the temperatures are low at this local time as well (Fig. 3d). The observed average density around midnight during these events is lower than at dawn, but it is generally above $1 \mathrm{~cm}^{-3}$. In addition, the temperatures at midnight in Fig. $3 \mathrm{~d}$ are observed to be relatively high at all epoch times in comparison with those for the midnight events in Fig. $3 \mathrm{c}$ near zero epoch. Thus, the occurrence of cold, dense plasma at dawn is often correlated with non-negligibly high plasma density near midnight (and, indeed, throughout most of the nightside), but this plasma is not typically (1) colder than usual and (2) as dense as $2 \mathrm{~cm}^{-3}$ (i.e., since it was not recorded in the original selection using our density and temperature thresholds).

\subsection{Transport patterns of the different plasma populations}

Figure 4 shows the superposed epoch plots of the relative number of cold $(<5 \mathrm{keV})$, dense $\left(>2 \mathrm{~cm}^{-3}\right)$ ion measurements subsequent to an initial midnight (panel a) or dawn (panel b) event. The panels show the absolute number of such measurements, normalized by the total number of all measurements, in each local time - epoch time bin. In these plots, grey means that no cold, dense measurement is recorded at all. This representation is meant to follow local time changes in such cold, dense plasma observations over the course of the events, which may shed light on the transport of these populations.

Figure 4a shows that, for the midnight events, there appears little counterpart at dawn, near zero epoch, in terms of the relative number of such measurements. Similarly, little counterpart is observed at midnight, around zero epoch, for the dawn events (Fig. 4b), as expected from the results of the previous analyses (e.g., Fig. 3). A non-negligible but small occurrence (0.01 to 0.1$)$ is observed towards dawn as epoch time progresses in Fig. 4a. This figure shows that the frequency of cold, dense plasma observations is relatively high along the corotation curve (white dashed line), suggesting that cold, dense plasma from midnight may convect dawnward and be detected there for a minority of the midnight events. But the detection frequency is also appreciable throughout the entire dawnside, from zero epoch onwards. This means that, for midnight events, cold and dense plasma is sometimes observed at dawn before corotation could deliver it from the midnight regions. However, the generally low frequency of observation outside of the region of initial detection (for both Figs. 4a and 4b) is also compatible with the fact that observation of both types of populations during the same event is not very frequent, and that the two populations are distinct in origin. 

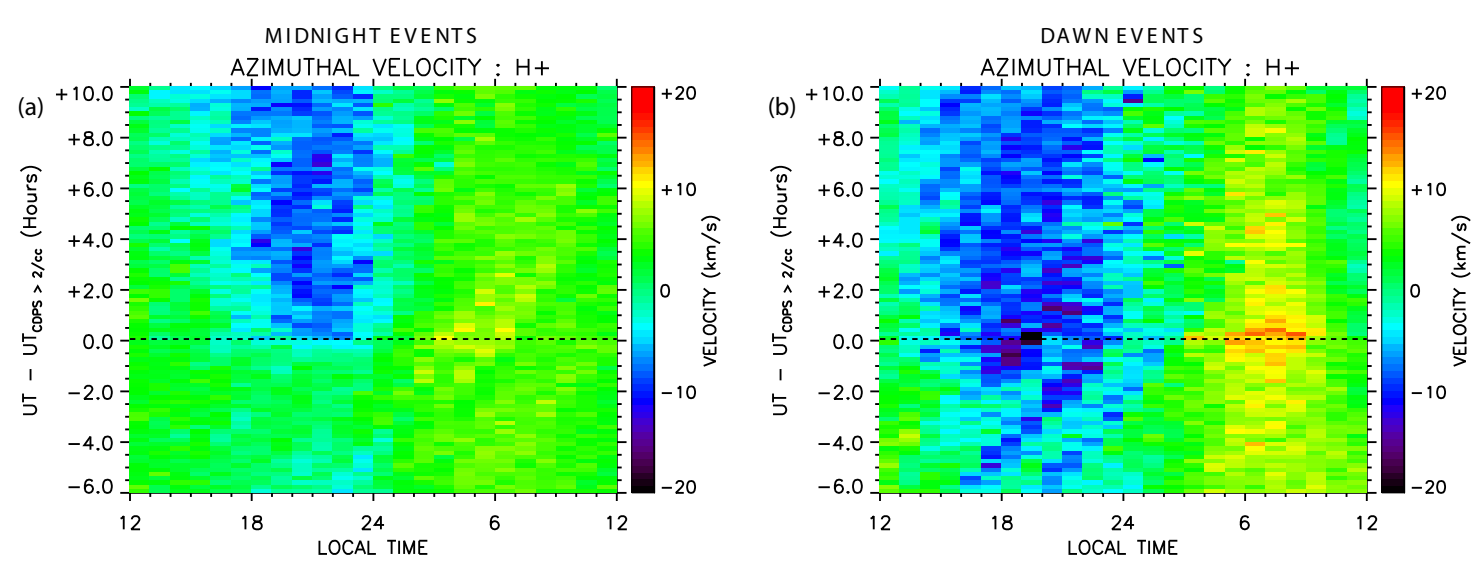

Fig. 5. Superposed epoch distribution of the azimuthal (eastward) ion velocity component for the midnight and dawn events. The positive (yellow to red) values at dawn correspond to sunward flow. The negative values (blue) at dusk correspond to sunward flows as well. See text and previous figure captions for further details.

It is important to note the presence of few cold, dense measurements near midnight before zero epoch in the case of the dawn events in Fig. 4b (and some counts in Fig. 4a as well). Although these are compatible with the detection of both types of cold, dense populations during the same events, such measurements ought not to be measured at such time, i.e., before zero epoch, according to our original selection criteria. The existence of non-zero counts prior to zero epoch in these figures is partially due to individual data points that do not satisfy the two-in-a-row cold, dense measurements criterion (see Sect. 2.1). It is also largely the result of our minimum lag time criteria of $12 \mathrm{~h}$ between two consecutive events, i.e., these counts were likely occurring during the few hours following previously selected events which happened at an earlier time on the dusk- or day-side.

The MPA instruments measure the 3-D distribution functions and thus allow the determination of the bulk flow velocity. For flow speeds significantly smaller than the thermal speeds, this is a difficult measurement and shows significant scatter. Nonetheless, we may examine the derived velocities for the events in this study. Figure 5 shows the superposed epoch plot of the eastward velocity measured for the midnight (panel a) and dawn (panel b) events in a format similar to Fig. 3. At dawn, eastward is equivalent to sunward, whereas at dusk eastward is equivalent to anti-sunward, and at midnight it is toward dawn. Because the satellites are all spinning around an axis pointing radially toward Earth, the east-west flow component is deemed to be the most reliable.

Figures $5 \mathrm{a}$ and $5 \mathrm{~b}$ show a global pattern of the ion flow being diverted around the Earth from the midnight region, with sunward-directed flows both on the dusk and dawn side of geosynchronous orbit. The important observations in these figures are (1) the sunward direction of the flows at both dawn and dusk during both types of events, and (2) that the flows are clearly enhanced during the dawn events compared to the midnight events. The former observation shows that the dawn population is not flowing anti-sunward, as would be expected for typical LLBL encounters. The latter observation shows a global convection enhancement consistent with the more disturbed periods corresponding to the dawn events.

\subsection{Global properties of the source ion populations}

In this section we wish to investigate the origin of the populations for each type of event. We investigate the global properties of the tail plasma sheet (which may include LLBL) regions using a mapping technique of data from the DMSP spacecraft fleet (see Sect. 2.3 and, e.g., Wing and Newell, 1998). Figure 6 shows the total number of measurements to be used in the averages of Figs. 7 and 8. The representation shows the equatorial plane of the magnetotail, for the midnight and dawn events, respectively, in the left and right column, and for three different epoch time intervals relative to the geosynchronous event identification ( -6 to 0,0 to +4 , and +4 to +10 in hours).

Figure 6 shows that the coverage of DMSP data in the plasma sheet is particularly good on both flanks and in the near-Earth regions. The central and distant part of the plasma sheet is the least well covered region.

Figure 7 shows the average ion density (left column) and temperature (right column) of the plasma sheet for the three different epoch time intervals relative to the onset of the midnight events. It shows that, except at its outer edge, the plasma sheet on the flanks before zero epoch (Figs. 7a and $7 \mathrm{~b}$ ) is substantially denser and colder (and especially on the dawn side) compared to that observed after zero epoch (Figs. 7c, 7d, 7e and 7f). As noted in Fig. 2, before zero epoch, the IMF is northward on average for these events, while it turns southward and stays horizontal on average from zero epoch onwards. Around midnight close to zero epoch (in the time interval 0-4) in Fig. 7c, there appears a particularly dense ion population. This population is presumably 
Midnight events
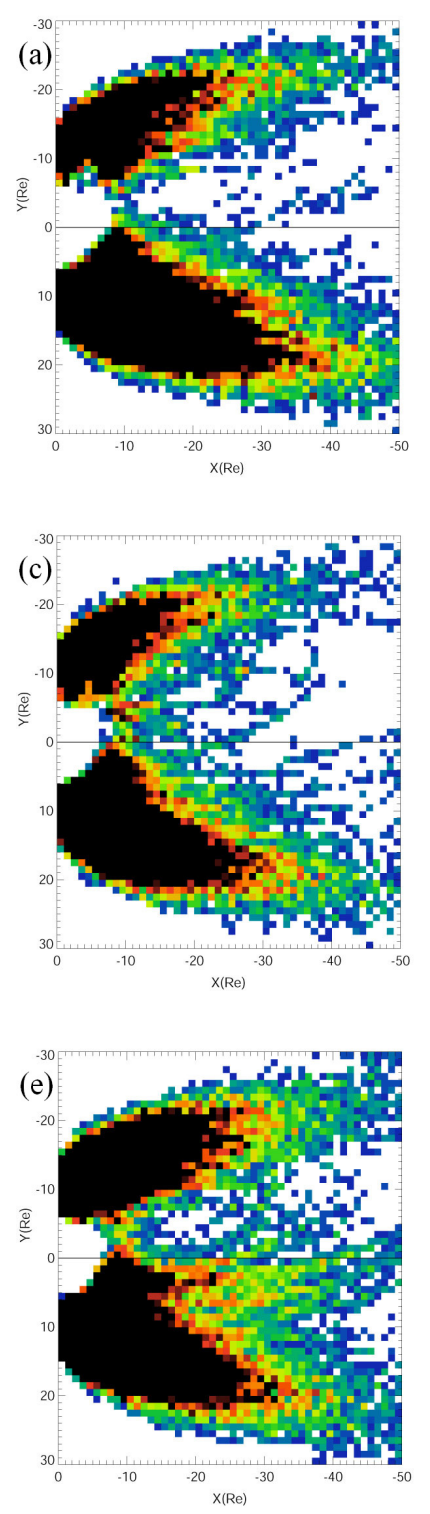

Dawn events
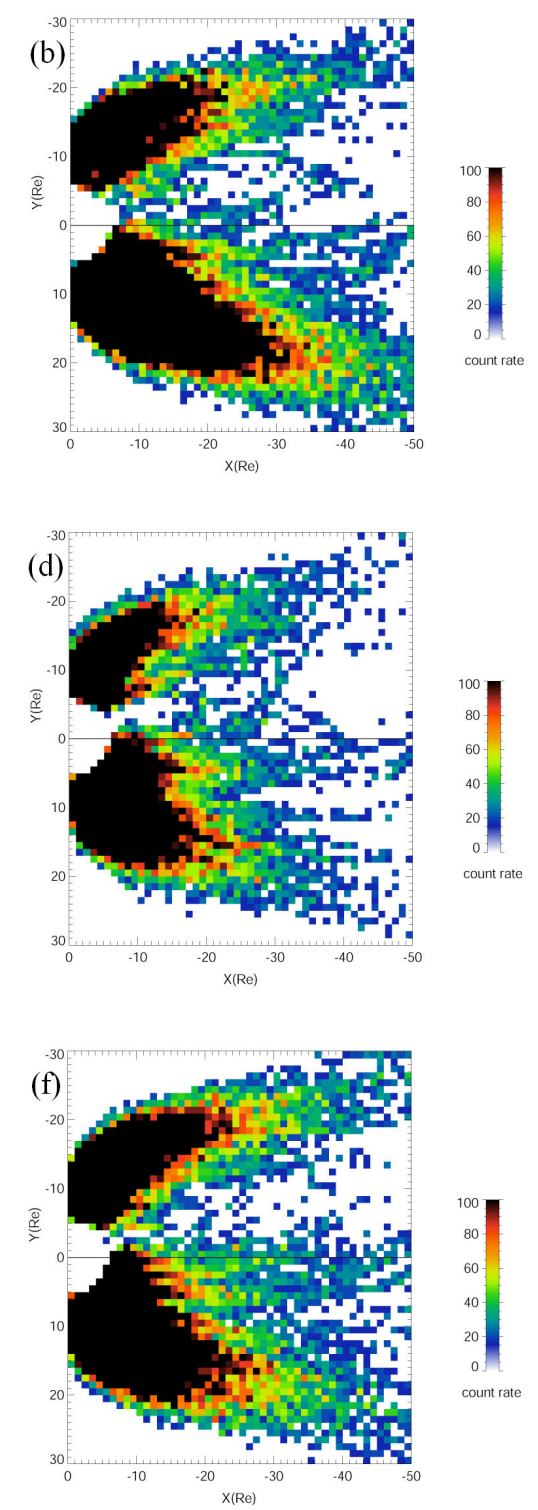

Fig. 6. Two-dimensional spatial plots of the number of measurements obtained in the nightside plasma sheet from the mapping of lowaltitude DMSP data into the equatorial plane. Data corresponding to the midnight (dawn) events are shown in the left (right) column. DMSP measurements are binned according to three distinct epoch time intervals ( -6 to 0,0 to +4 , and +4 to $+10 \mathrm{~h}$ ) in order to be compared with the previous analysis of geosynchronous spacecraft data. The sun is to the left and the dawn side of the magnetosphere is to the top of the panels. The grid labels are given in Earth radii $\left(R_{E}\right)$.

associated with that observed at midnight around zero epoch in Los Alamos data. The number of measurements in this region of the representation of Fig. $6 \mathrm{c}$ is relatively high, so that this property may be viewed as characteristic of this population. Unfortunately, the low data coverage in the more distant, central region of the plasma sheet does not allow us to observe the origin of the population at earlier epoch times.

Figure 8 shows the same representations as Fig. 7 but for the dawn events. Compared to that observed before zero epoch for the midnight events in Figs. 7a and $7 \mathrm{~b}$ (i.e., that coldest and densest), the plasma sheet seems somewhat less dense and significantly hotter at all epoch times in the case of the dawn events. These dawn events are not associated with northward IMF (Fig. 2), but rather with strong southward average IMF, especially before zero epoch.

In Fig. 8a, large densities are observed on the dawn side of the magnetosphere before as well as after zero epoch. This tendency for densities to be higher at dawn than at dusk is 


\section{Midnight events}
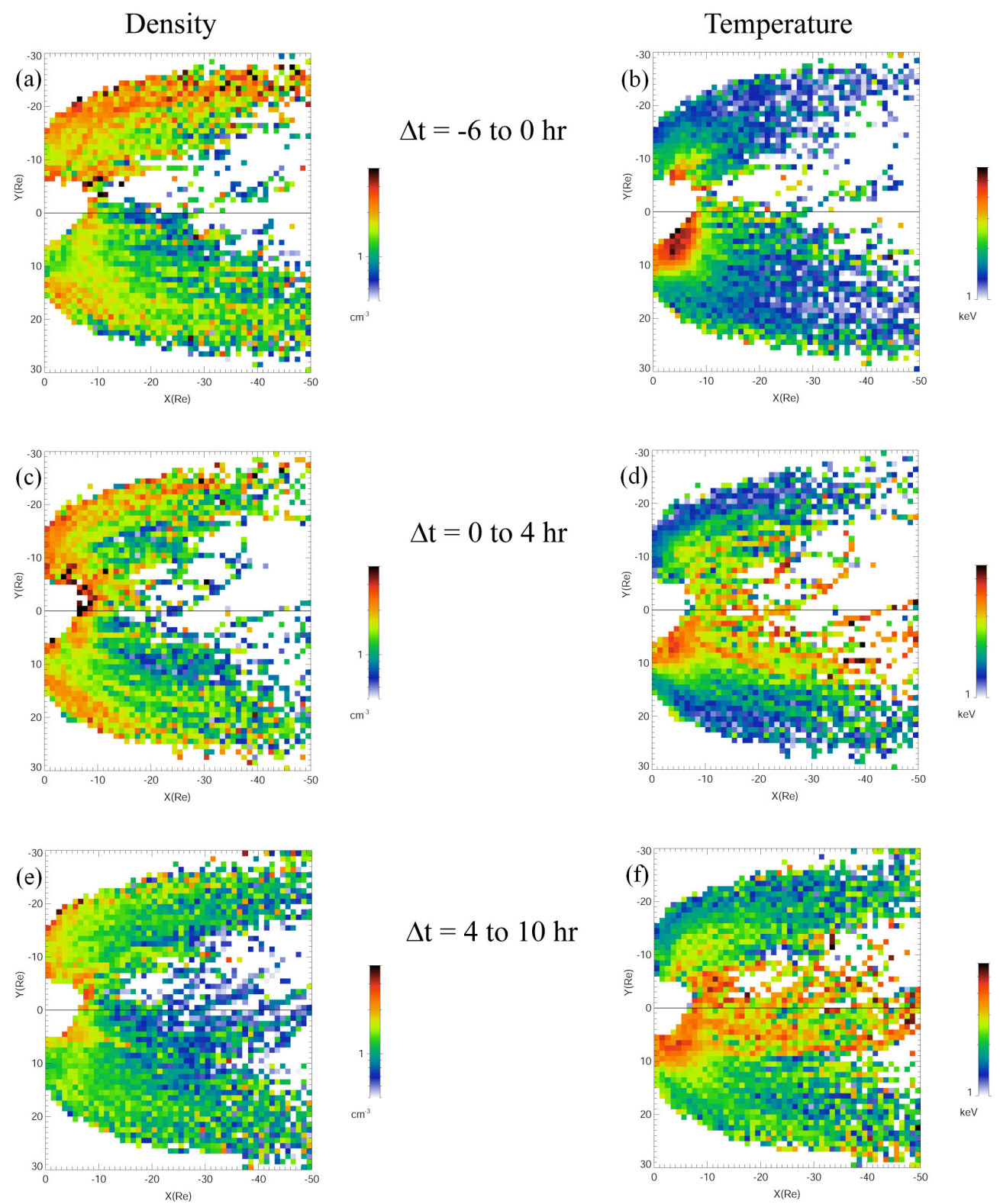

Fig. 7. Two-dimensional spatial plots of the DMSP ion density (left) and temperature (right) for the 331 midnight events, for the three different epoch time intervals of interest. See Fig. 6 caption and text for further details.

observed in all plots of Figs. 7 and 8, thus regardless of the type of event (see also Wing et al., 2005). Similarly, the dawn flank of the plasma sheet is significantly colder than the dusk side for both kinds of events, at all epoch times. This difference is observable as a layer of cold plasma all along the dawn flank, which has no counterpart on the dusk flank of the plasma sheet.

\section{Discussion}

\subsection{Existence of two distinct ion populations}

From the results of Sect. 3, we may first recall that initial measurements of cold $(T<5 \mathrm{keV})$, dense $\left(N>2 \mathrm{~cm}^{-3}\right)$ plasma appear distinctly at both midnight and dawn with comparable occurrences. That the local time distribution shows two peaks at midnight and dawn, with a large dip in between (Fig. 1a), shows that those are generally distinct populations. It is known that the plasma sheet ion 

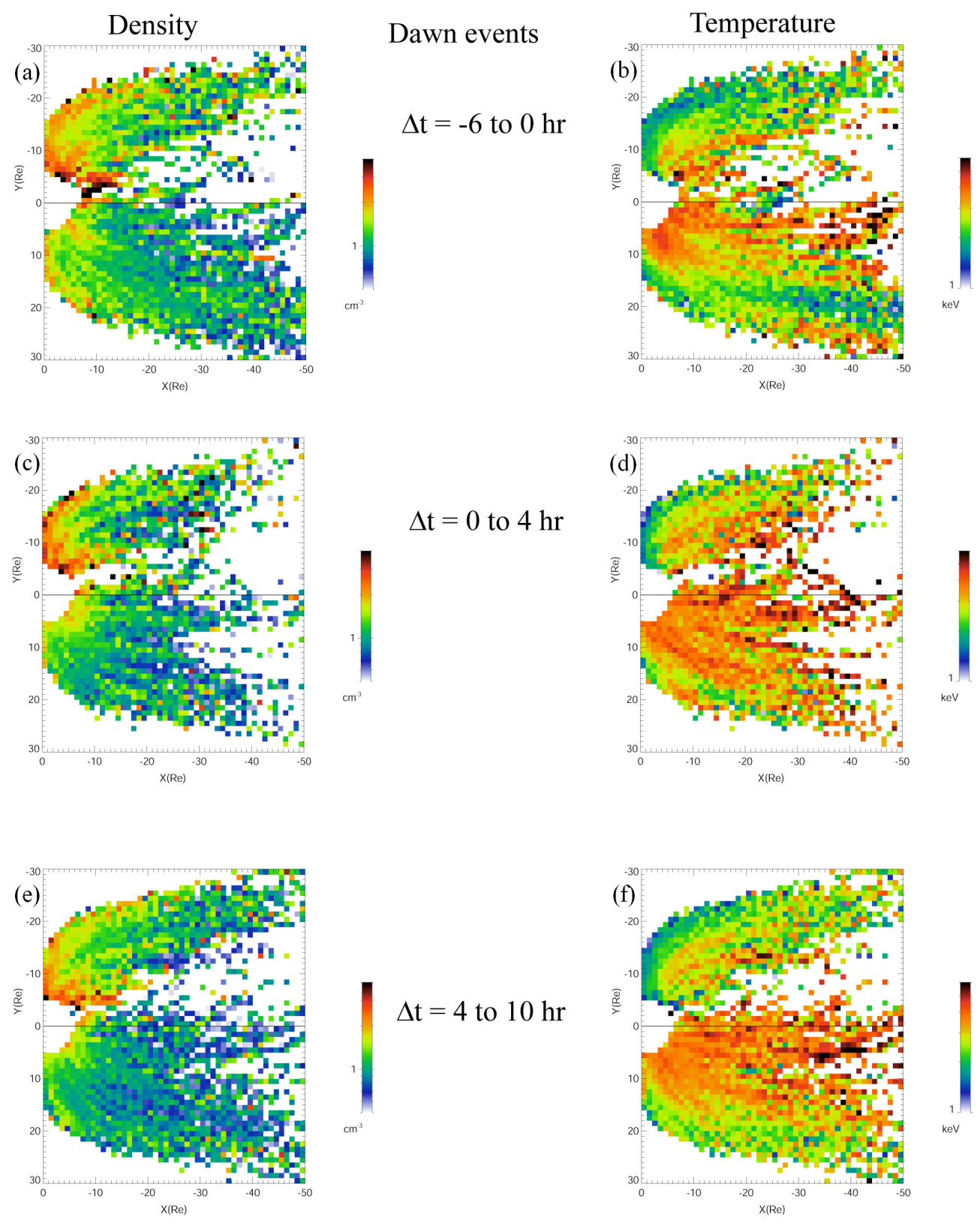

Fig. 8. Two-dimensional spatial plots of the DMSP ion density (left) and temperature (right) for the 234 dawn events, for the three different epoch time intervals of interest. See Fig. 6 caption and text for further details.

temperature at geosynchronous orbit decreases from dusk to dawn on the nightside (Maurice et al., 1998; Korth et al., 1999; Denton et al., 2005), but this cannot account for the two peaks observed in this survey.

In Sect. 3, Fig. 1c, we noted that the total number of cold, dense events at dawn generally increases when the temperature threshold is decreased (with fixed density threshold at $2 \mathrm{~cm}^{-3}$ ). This feature is due to the fact that a fraction of the dense and relatively hot events from midnight (these events are numerous; i.e., the red curve around the midnight region in Fig. 1c) are recorded during events when a colder and dense population is observed at dawn as well. Thus, by decreasing the temperature threshold, the midnight population no longer qualifies, but the dawn, colder population seen later during the same event becomes the first to satisfy the criteria. This fact demonstrates that some events are characterized by dense plasma at both midnight and dawn, but for many of those events only the dawn plasma is unusually cold. Some of the cold, dense events recorded at midnight do appear to have a cold, dense counterpart at dawn as well (Fig. 3c). Although the two kinds of populations may be seen during the same event, comparison with the expected corotation time 
of cold plasma from midnight (Fig. 4a) shows that the dawn population is not entirely attributable to corotation from the initial midnight appearance. As further shown in Fig. 4, the observation of the two populations during the same event has a low occurrence frequency overall.

\subsection{Origin and fate of the midnight population}

The change observed in the average IMF direction (from northward to horizontal) just before zero epoch for the midnight events in Figs. 2d and $2 \mathrm{f}$ presumably results in the slight enhancement of magnetospheric convection observed as a modest gradual rise in the average $K_{p}$ of Fig. 2i. This convection enhancement would allow the plasma sheet to be pushed closer to Earth, compatible with previous observations (Korth and Thomsen, 2001; Thomsen, 2005). As the IMF orientation preceding the observation of cold, dense plasma at midnight is substantially northward on average, it is interpreted that the source of this population is the cold, dense plasma sheet (CDPS) formed, and present in the midnight tail regions during such northward IMF conditions (Terasawa et al., 1997; Fujimoto et al., 1998), as previously suggested (Thomsen et al., 2003).

The observation of a modest $K_{p}$ enhancement and insignificant average $D_{s t}$ decrease around zero epoch for the midnight events (Fig. 2) suggest that the presence of cold, dense plasma at midnight of geosynchronous orbit does not typically lead to enhanced geomagnetic activity. Such activity requires sustained southward IMF, which does not necessarily follow (and is not observed in Fig. 2) the intervals of sustained northward IMF required to produce the CDPS in the midnight region.

Assessing whether the formation of a CDPS in the midnight tail of the magnetosphere may enhance ensuing geomagnetic activity requires the study of specific geoeffective events with and without prior formation of a CDPS. Such a study has been undertaken in a previous report (Lavraud et al., 2006b), which showed that storms preceded by intervals of northward IMF tend to be modestly stronger than those not preceded by northward IMF, and this difference is presumably attributable to the higher plasma sheet densities observed under these conditions.

\subsection{Origin and fate of the dawn population}

By contrast, the cold, dense ion population detected initially at dawn is not preceded by northward IMF. Therefore, it cannot be simply associated with the cold, dense or hot, dense ion populations reported at dawn and in the nightside by $\mathrm{Fu}-$ jimoto et al. (1998; 2005) using Geotail data. Rather, the dawn population observed here follows from a substantial southward IMF in the preceding $4 \mathrm{~h}$, which in turn leads to a significant geomagnetic activity (observed in $K_{p}, A_{E}$ and $D_{s t}$ in Fig. 2). It is of particular interest to notice that the appearance of this population at dawn is actually observed after the main phase, i.e., at the end of the main decrease in $D_{s t}$, down to $-50 \mathrm{nT}$ on average. This observation demonstrates that this cold and dense population is not the source of the ring current increase during the main phase. In other words, it is the solar wind conditions, with associated compression (dynamic pressure) and large-scale convection ( $K_{p}$ index), that seem to lead to both the large geomagnetic activity and the access of the cold, dense plasma population at dawn. It is presently unclear whether this population in turn affects the ring current strength in the later stage of the storm. Future work, involving simulations of the ring current, will be needed to study this possibility.

Observation of cold and dense plasma at the dawn side of geosynchronous orbit following enhanced magnetospheric compression (large solar wind dynamic pressure) and activity (convection) could suggest that these populations come from magnetosheath and LLBL encounters at geosynchronous orbit. Since we reject samples with densities above $10 \mathrm{~cm}^{-3}$ or ion flow speeds above $100 \mathrm{~km} / \mathrm{s}$ in all of our analysis, magnetosheath intervals are unlikely to contribute, and only lowspeed LLBL could have been included. Since the cold and dense population observed at dawn is not symmetrically observed at dusk, it seems unlikely that this feature is caused by such LLBL encounters either. Additionally, Fig. 5 shows an enhancement of the sunward flow at dawn and dusk around zero epoch (from 5 to $\sim 15 \mathrm{~km} / \mathrm{s}$ ), whereas the LLBL would be expected to flow tailward there. This sunward flow enhancement is compatible with a global enhancement of magnetospheric compression and convection during the active times corresponding to the dawn events. The possibility of a dawn-dusk asymmetry in the magnetopause and LLBL positions is further discussed in Sect. 4.4.

We have attempted to estimate the composition from the difference between derived ion and electron densities (cf. Denton et al., 2005; Lavraud et al., 2005). In both kinds of events we infer lower than usual contribution from heavier ion populations (not shown). This suggests a more direct solar wind origin for both populations. But this result is not fully conclusive owing to the limitations of the technique. Further work will be required to evaluate a possible ionospheric contribution. Finally, it is straightforward to mention that the solar wind driving conditions identified here for both types of events come from a large-scale statistical analysis. Therefore, it may be expected that various combinations of such drivers/criteria ( $K_{p}$, IMF $B_{z}$ and solar wind density in particular) may actually lead to the observation of cold, dense plasma at geosynchronous orbit, without necessarily requiring all of them to be met.

\subsection{Global plasma sheet observations and transport}

Previous works using large-scale plasma sheet mapping with DMSP data have shown the capabilities of this technique (Wing and Newell, 2002; Wing et al., 2005). These studies demonstrated that the plasma sheet globally becomes denser 
and colder when the IMF is northward and that there exists a persistent tendency for the dawn side of the plasma sheet to display these characteristics more than the dusk side.

In the context of the present study, the cold, dense plasma sheet (CDPS) origin of the midnight events is confirmed through the observations from DMSP satellites. The plasma sheet and flank regions are substantially colder and denser before than after zero epoch for the midnight events (Fig. 7), compatible with the formation and existence of a CDPS under the corresponding northward IMF. Near zero epoch, a significantly dense population appears in the near-Earth region in the midnight sector, consistent with the geosynchronous observations at that time. Unfortunately, the low coverage in the more distant midnight region does not allow us to trace this population fully.

The results from DMSP data also show that the plasma sheet is not typically cold or dense during the dawn events, consistent with the more southward or horizontal IMF during those times. There appears, however, a layer of denser and substantially colder plasma along the dawn flanks at all epoch times during both kinds of events. The DMSP observations thus show the existence of a cold and dense population (in the form of a layer in Figs. 7 and 8) on the dawn side of the plasma sheet, not present at dusk, which may be interpreted as the source population of the population observed at dawn of geosynchronous orbit during the dawn events. Its access to geosynchronous orbit may be the result of the more extreme solar wind conditions which are conducive to enhanced compression and convection in the magnetosphere, i.e., it occurs during active times. This is suggestive of plasma transport from the dawn flank toward the inner, dawn magnetosphere during such times. Such transport pattern was also suggested as a fate for the cold, dense and hot, dense ion events reported in the mid-tail at dawn by Fujimoto et al. $(1998,2005)$ from the analysis of Geotail data. However, we have shown that the dawn events studied here are not preceded by northward IMF and are therefore of different origin to those discussed by Fujimoto et al. (1998, 2005).

The recent analysis of geosynchronous magnetopause crossings by Dmitriev et al. (2004) showed that the occurrence frequency for such crossings is skewed toward the dawn side (with the peak occurrence between 10:0011:00 LT). Such an asymmetry may lead to more frequent crossings of the LLBL under disturbed conditions and could be a reason for our results, i.e., large occurrence for cold and dense plasma observations at dawn but not at dusk. However, because (1) the cold, dense plasma occurrence at 10:00-11:00 LT (and at noon to dusk LT) is particularly low (Fig. 1a), (2) the flows are enhanced and sunward (rather than tailward) at dawn during the dawn events (Fig. 5), (3) the flows are similarly enhanced and sunward at dusk, but the plasma is neither cold or dense (Figs. 3 and 5), and (4) most importantly, a cold and dense ion population is mainly observed in the dawn-side of the plasma sheet (DMSP data in Figs. 7 and 8), we may conclude that the dawn events do not generally correspond to LLBL crossings. That cold, dense plasma is preferentially observed at dawn of geosynchronous orbit is likely explained by the preference for the plasma sheet in the tail to be denser and colder at dawn. This population may thus be interpreted as the source of the cold, dense events recorded at dawn of geosynchronous orbit. Finally, it is reminded that the appearance of the dawn population (and of the midnight one) seems unrelated to the IMF $B_{y}$ component.

\section{Conclusions}

We have reported the appearance of two distinct cold $\left(T_{i}<5 \mathrm{keV}\right)$, dense $\left(N_{i}>2 \mathrm{~cm}^{-3}\right)$ ion populations at midnight and dawn of geosynchronous orbit. These populations were studied using results from geosynchronous Los Alamos data, complemented by corresponding large-scale plasma sheet data obtained by mapping DMSP observations in the tail.

The first population is observed in the midnight region of geosynchronous orbit. The second population, which has drawn less attention, is detected on the dawn side of geosynchronous orbit. No such cold, dense population is observed on the dusk side of geosynchronous orbit on a frequent basis. The study of the spatial and temporal behavior of both populations has shown that they appear at geosynchronous orbit as distinct populations, since, usually, the appearance of the midnight population is not associated with that of the dawn population, and vice versa.

The midnight population is observed after a slight turning of the IMF towards more horizontal direction on average, following a period of substantial northward IMF. The observation of this population is thus interpreted as the result of the inward transport of the cold, dense plasma sheet (CDPS) following a moderate enhancement of magnetospheric convection, as suggested by Thomsen et al. (2003).

The dawn, cold and dense ion population is associated with previously strong southward IMF and is on average observed around the end of the main phase of the corresponding $D_{s t}$ decrease. It is unlikely that the cold, dense population observed at dawn be the result of the direct inward motion of the low-latitude boundary layer (LLBL) because (1) no symmetric dusk population is observed and (2) an average small sunward flow $(\sim 15 \mathrm{~km} / \mathrm{s})$ is observed for those events. The dawn population is observed during active times (based on $D_{s t}, K_{p}$ and $A_{E}$ indices) in comparison with the midnight case. However, since the dawn population is observed only around the end of the main $D_{s t}$ decrease, it is concluded that this population does not generally contribute to the $D_{s t}$ decrease during the main phase. Rather, it may have access to geosynchronous orbit by means of a large compression and convection enhancement in the magnetosphere. Cold, dense ion populations thus preferentially get access to the inner magnetosphere from the dawn side during active times. 
This result is supported by the observation of the tail plasma sheet (from DMSP observations) to be significantly colder and denser at dawn than at dusk. This tail dawn-side population may thus be interpreted as the source of the dawn events recorded at geosynchronous orbit. Whether an additional, preferential transport pattern may also exist at dawn remains to be fully explored.

To fully examine the fate of these two populations and their implications for large-scale magnetospheric dynamics and geomagnetic activity, our future investigations will focus on analysis of specific case studies (not done here) combined with simulations of the ring current using appropriate boundary conditions as observed by geosynchronous spacecraft.

Acknowledgements. Work at Los Alamos was performed under the auspices of the US Department of Energy, with support from NASA programs (Guest investigator and Living With a Star TR\&T). S. W. gratefully acknowledges the support of NASA Grant NNG04GN14G and NSF Grant ATM-0538513.

Topical Editor I. A. Daglis thanks two referees for their help in evaluating this paper.

\section{References}

Bame, S. J., McComas, D. J., Thomsen, M. F., Barraclough, B. L., Elphic, R. C., Glore, J. P., Gosling, J. T., Chavez, J. C., Evans, E. P., and Wymer, J. F.: Magnetospheric plasma analyzer for spacecraft with restrained resources, Rev. Sci. Instrum., 64, No. 4, 1026-1033, 1993.

Bernstein, W., Hultqvist, B., and Borg, H.: Some implications of low altitude observations of isotropic precipitation of ring current protons beyond the plasmapause, Planet. Space Sci., 22, 767776, 1974.

Borovsky, J. E., Thomsen, M. F., and McComas, D. J.: The superdense plasma sheet: Plasmapheric origin, solar wind origin, or ionospheric origin?, J. Geophys. Res., 102, 22 089-22 097, 1997.

Borovsky, J. E.., Thomsen, M. F., Elphic, R. C., Cayton, T. E., and McComas, D. J.: The transport of plasma sheet material from the distant tail to geosynchronous orbit, J. Geophys. Res., 103, 20 297-20331, 1998.

Burton, R. K., McPherron, R. L., and Russell, C. T.: An empirical relationship between interplanetary conditions and Dst, J. Geophys. Res., 80, 31, 4204-4214, 1975.

Denton, M. H., Thomsen, M. F., Korth, H., Lynch, S., Zhang, J.-Ch., and Liemohn, M. W.: Bulk plasma properties at geosynchronous orbit, J. Geophys. Res., 110, A7, A07223, doi:10.1029/2004JA010861, 2005.

Dessler, A. J., and Parker, E. N.: Hydromagnetic theory of geomagnetic storms, J. Geophys. Res., 24, 2239-2252, 1959.

Dmitriev, A. V., Suvorova, A. V., Chao, J. K., and Yang, Y.-H.: Dawn-dusk asymmetry of geosynchronous magnetopause crossings, J. Geophys. Res., 109, A05203, doi:10.1029/2003JA010171, 2004.

Fujimoto, M., Terasawa, T., Mukai, T., Saito, Y., and Yamamoto, T.: Plasma entry from the flanks of the near-Earth magnetotail: Geotail observations, J. Geophys. Res., 103, 4391-4408, 1998.
Fujimoto, M., Mukai, T., and Kokubun, S.: Cold-dense plasma sheet and hot-dense ions in the inner magnetosphere, Adv. Space Res., 30, 10, 2279-2288, 2002.

Fujimoto, M., Mukai, T., and Kokubun, S.: The structure of the plasma sheet under northward IMF, in: Frontiers in Magnetospheric Plasma Physics, COSPAR colloquia Ser., edited by: Hoshino, M., Omura, Y., and Lanzerotti, L. J., Elsevier, 16, 1927, 2005.

Hardy, D. A., Schmitt, L. K., Gussenhoven, M. S., Marshall, F. J., Yeh, H. C., Shumaker, T. L., Hube, A., and Pantazis, J.: Precipitating electron and ion detectors (SSJ/4) for the block 5D/flights 6-10 DMSP satellites: Calibration and data presentation, Rep. AFGL-TR-84-0317, Air Force Geophys. Lab., Hanscom Air Force Base, Mass., 1984.

Hasegawa, H., Fujimoto, M., Phan, T. D., Rème, H., Balogh, A., Dunlop, M. W., Hashimoto, C., and TanDokoro, R.: Rolledup Kelvin-Helmholtz vortices and associated solar wind entry at Earth's magnetopause, Nature, 430, 755-758, 2004.

Huang, C. Y. and Frank, L. A.: A statistical survey of the central plasma sheet, J. Geophys. Res., 99, 83-95, 1994.

Jordanova, V. K., Farrugia, C. J., Janoo, L., Quinn, J. M., Torbert, R. B., Ogilvie, K. W., Lepping, R. P., Steinberg, J. T., McComas, D. J., and Belian, R. D.: October 1995 magnetic cloud and accompanying storm activity: ring current evolution, J. Geophys. Res., 103, 79-92, 1998.

King, J. H. and Papitashvili, N. E.: Solar wind spatial scales in and comparisons of hourly Wind and ACE plasma and magnetic field data, J. Geophys. Res., 110, A2, A02209, doi:10.1029/2004JA010804, 2005.

Kistler, L. M., Mobius, E., Baumjohann, W., Paschmann, G., and Hamilton, D. C.: Pressure changes in the plasma sheet during substorm injections, J. Geophys. Res., 97, 2973-2983, 1992.

Korth, H., Thomsen, M. F., Borovsky, J. E., and McComas, D. J.: Plasma sheet access to geosynchronous orbit, J. Geophys. Res., 104, 25 047-25 061, 1999.

Korth, H., and Thomsen, M. F.: Plasma sheet access to geosynchronous orbit: Generalization to numerical field models, J. Geophys. Res., 106, 29655-29667, 2001.

Kozyra, J. U., Jordanova, V. K., Borovsky, J. E., Thomsen, M. F., Knipp, D. J., Evans, D. S., McComas, D. J., and Cayton, T. E.: Effects of a high-density plasma sheet on ring current development during the November 2-6, 1993, magnetic storm, J. Geophys. Res., 103, 26 285-26305, 1998.

Lavraud, B., Denton, M. H., Thomsen, M. F., Borovsky, J. E., and Friedel, R. H. W.: Superposed epoch analysis of dense plasma access to geosynchronous orbit, Ann. Geophys., 23, 2519-2529, 2005 , http://www.ann-geophys.net/23/2519/2005/.

Lavraud, B., Thomsen, M. F., Lefebvre, B., Schwartz, S. J., Seki, K., Phan, T. D., Wang, Y. L., Fazakerley, A., Rème, H., and Balogh, A.: Evidence for newly closed magnetosheath field lines at the dayside magnetopause under northward IMF, J. Geophys. Res., 111, No. A5, A05211, doi:10.1029/2005JA011266, 2006a.

Lavraud, B., Thomsen, M. F., Borovsky, J. E., Denton, M. H., and Pulkkinen, T. I.: Magnetosphere preconditioning under northward IMF: Evidence from the study of CME and CIR geoeffectiveness, J. Geophys. Res., 111, A09208, doi:10.1029/2005JA011566, 2006b.

Lennartsson, W. and Shelley, E. G.: Survey of $0.1-$ to $16-\mathrm{keV} / \mathrm{e}$ 
plasma sheet ion composition, J. Geophys. Res., 91, 3061-3076, 1986.

Lennartsson, W.: A scenario for solar wind penetration of earth's magnetic tail based on ion composition data from the ISEE 1 spacecraft, J. Geophys. Res., 97, 19221-19238, 1992.

Lyons, L. R. and Speiser, T. W.: Evidence for current sheet acceleration in the geomagnetic tail, J. Geophys. Res., 87, 2276-2286, 1982.

Maurice, S., Thomsen, M. F., McComas, D. J., and Elphic, R. C.: Quiet time densities of hot ions at geosynchronous orbit, J. Geophys. Res., 103, A8, 17 571-17 585, 1998.

McComas, D. J., Bame, S. J., Barraclough, B. L., Donart, J. R., Elphic, R. C., Gosling, J. T., Moldwin, M. B., Moore, K. R., and Thomsen, M. F.: Magnetospheric Plasma Analyzer: Initial threespacecraft observations from geosynchronous orbit, J. Geophys. Res., 98, 13 453-13 465, 1993.

Newell, P. T., Sergeev, V. A., Bikkuzina, G. R., and Wing, S.: Characterizing the state of the magnetosphere: Testing the ion precipitation maxima latitude (b2i) and the ion isotropy boundary, J. Geophys. Res., 103, 4739-4745, 1998.

Newell, P. T. and Wing, S.: Remotely imaging the plasma sheet with low-altitude satellite clusters, J. Atm. Sol. Terr. Phys., 62, 10, 851-863, 2000.

Øieroset, M., Raeder, J., Phan, T. D., Wing, S., McFadden, J. P., Li, W., Fujimoto, M., Rème, H., and Balogh, A.: Global cooling and densification of the plasma sheet during an extended period of purely northward IMF on 22-24 October, 2003, Geophys. Res. Lett., 32, No. 12, L12S07, doi:10.1029/2004GL021523, 2005.

Phan, T. D., Lin, R. P., Fuselier, S. A., and Fujimoto, M.: Wind observations of mixed magnetosheath-plasma sheet ions deep inside the magnetosphere, J. Geophys. Res., 105, 5497-5505, 2000.

Raeder, J., Berchem, J., Ashour-Abdalla, M., Frank, L. A., Patterson, W. R., Ackerson, K. L., Kokubun, S., Yamamoto, T., and Slavin, J. A.: Boundary layer formation in the magnetotail: Geotail observations and comparisons with a global MHD simulation, Geophys. Res. Lett., 24, No. 8, 951-954, 1997.

Sergeev, V. A., Malkov, M., and Mursula K.: Testing the isotropic boundary algorithm method to evaluate the magnetic field configuration in the tail, J. Geophys. Res., 98, 7609-7620, 1993.
Song, P. and Russell, C. T.: Model of the formation of the lowlatitude boundary layer for strongly northward interplanetary magnetic field, J. Geophys. Res., 97, No. A2, 1411-1420, 1992.

Terasawa, T., Fujimoto, M., Mukai, T., Shinohara, I., Saito, Y., Yamamoto, T., Machida, S., Kokubun, S., Lazarus, A. J., Steinberg, J. T., and Lepping, R. P.: Solar wind control of density and temperature in the near-Earth plasma sheet: WIND/GEOTAIL collaboration, Geophys. Res. Lett., 24, No. 8, 935-938, 1997.

Thomsen, M. F., Borovsky, J. E., McComas, D. J., and Collier, M. R.: Variability of the ring current source population, Geophys. Res. Lett., 25, 18, 3481-3484, 1998.

Thomsen, M. F., Noveroske, E., Borovsky, J. E., and McComas, D. J.: Calculation of moments from measurements by the Los Alamos magnetospheric plasma analyzer, LA Rep. LA-13566MS, Los Alamos Nat. Lab., Los Alamos, N. M., 1999.

Thomsen, M. F., Borovsky, J. E., Skoug, R. M., and Smith, C. W.: Delivery of cold, dense plasma sheet material into the near-Earth region, J. Geophys. Res., 108, A4, 1151, doi:10.1029/2002JA009544, 2003.

Thomsen, M. F., Why Kp is such a good measure of magnetospheric convection?, Space Weather, 2, doi:10.1029/2004SW000089, 2005.

Tsyganenko, N. A.: A magnetospheric magnetic field model with a warped tail current sheet, Planet Space Sci., 37, 5-20, 1989.

Vasyliunas, V. M.: Reinterpreting the Burton-McPherron-Russell equation for predicting $D_{s t}$, J. Geophys. Res., 111, A07S04, doi:10.1029/2005JA011440, 2006.

Wing, S. and Newell, P. T.: Central plasma sheet ion properties as inferred from ionospheric observations, J. Geophys. Res., 103, 6785-6800, 1998.

Wing, S. and Newell, P. T.: 2D plasma sheet ion density and temperature profiles for northward and southward IMF, Geophys. Res Lett., 29, doi:10.1029/2001GL013950, 2002.

Wing, S., Johnson, J. R., Newell, P. T., and Meng, C.-I.: Dawn-dusk asymmetry in the northward IMF plasma sheet, J. Geophys. Res., 110, A08205, doi:10.1029/2005JA011086, 2005.

Zwolakowska, D., Koperski, P., and Popielawska, B.: Plasma populations in the tail during northward IMF, Proceedings of the international conference on substorms (ICS-1), ESA SP-335, 57-63, 1992. 